Int. J. Electrochem. Sci., 15 (2020) 4368 - 4378

International Journal of

ELECTROCHEMICAL

SCIENCE

WWW.electrochemsci.org

\title{
Inhibition Effect and Mechanism of 2-(3-bromophenyl)-1- phenyl-1H-Benzimidazole on Copper Corrosion in Acidic Solution
}

\author{
Jinliang Zhang, ${ }^{1, *}$, Hao $\mathrm{Li}^{2}$ \\ ${ }^{1}$ School of Materials and Chemical Engineering, Ningbo University of Technology, Ningbo \\ Zhejiang 315211, China \\ ${ }^{2}$ School of Chemistry and Chemical Engineering, Chongqing University, Chongqing, 400044, \\ China \\ *E-mail: zhangjinliang_nut@126.com (J. Zhang)
}

doi: $10.20964 / 2020.05 .65$

Received: 8 Janaury 2020 / Accepted: 14 February 2020 / Published: 10 April 2020

The inhibition effect of (2-(3-Bromophenyl)-1-phenyl-1H-benzimidazole, BPB) was investigated for inhibiting copper corrosion in $0.5 \mathrm{~mol} \mathrm{~L}^{-1} \mathrm{H}_{2} \mathrm{SO}_{4}$ solution, compared with traditional corrosion inhibitor benzimidazole (BIM). Various methods were used including electrochemical methods, scanning electron microscope (SEM), Langmuir type adsorption isotherm, quantum chemical calculation, and molecular dynamics simulation. We found that BPB belongs to a mixed type inhibitor. The adsorption of BPB on $\mathrm{Cu}$ conforms to a Langmuir adsorption isotherm. The maximum efficiencies of $70.1 \%$ for BIM was improved to $97.0 \%$ at $5 \mathrm{mmol} \mathrm{L}^{-1}$. SEM confirms the electrochemical results. Molecular chemical calculation further reveals the inhibition mechanism of BPB at microscopic level and explain its greater inhibition ability than BIM.

Keywords: Inhibitor, Pure copper, $\mathrm{H}_{2} \mathrm{SO}_{4}$, Corrosion, Simulation.

\section{$\underline{\text { FULL TEXT }}$}

(C) 2020 The Authors. Published by ESG (www.electrochemsci.org). This article is an open access article distributed under the terms and conditions of the Creative Commons Attribution license (http://creativecommons.org/licenses/by/4.0/). 